\title{
Parameterisation of sediment geochemistry for simulating water quality responses to long-term catchment and climate changes in polymictic, eutrophic Lake Rotorua, New Zealand
}

\author{
D. Özkundakci, C. G. McBride \& D. P. Hamilton \\ Environmental Research Institute, Department of Biological Sciences, \\ University of Waikato, New Zealand
}

\begin{abstract}
Numerical models of aquatic ecosystems that couple physics and biogeochemistry are valuable tools in aquatic ecosystem research. These models provide opportunities to test theories and to inform environmental management. In this study, we used the dynamic, process-based hydrodynamic-ecological model DYRESM-CAEDYM to simulate key ecosystem processes of Lake Rotorua, New Zealand, for six 8-year periods between 1920 and 2100 in order to evaluate the potential effects of future changes in land use and climate. Longterm variations in external boundary conditions (e.g. inflows) to the lake ecosystem are incorporated by varying the relevant input files in the DYRESMCAEDYM model. However, quantification of internal lake processes, specifically those at the sediment-water interface, presents a major challenge for long-term simulations. The sediment model within CAEDYM is 'static', with assumed constant sediment composition and a relatively simplistic process representation for nutrient and oxygen fluxes between sediment and water. Specifically, the model regulates sediment phosphate and ammonium release according to concentrations of oxidising species (i.e. oxygen and nitrate), and temperature in the overlying water layer. Sediment oxygen demand is controlled by dissolved oxygen concentrations and temperature in the water layer overlying the sediments. We used a 'trial and error' approach to estimate parameters for calibrating and validating the model, and regression modelling to infer the
\end{abstract}


parameters beyond the calibration/validation simulation period (2001-2009). We observed a significant relationship in historic monitoring data between the external nitrogen load to the lake and its hypolimnetic oxygen demand as well as the bottom-sediment nitrogen concentrations. This relationship was used to hindcast and forecast model parameters for sediment nutrient release and oxygen demand in the six model simulation periods. The inclusion of a dynamic response of sediment nutrient release and oxygen demand parameters to changes in external nutrient loads enabled a more conceptually concise simulation of water quality for the simulations. This model is currently being used by regional environmental management authorities for developing an Action Plan for the restoration of Lake Rotorua.

Keywords: DYRESM-CAEDYM, internal loading, sediment nutrient release, sediment oxygen demand, integrated modelling, phosphorus, nitrogen.

\section{Introduction}

In aquatic sciences, water quality models have long been used to analyse physical, chemical and/or trophic dynamics (Norberg and DeAngelis [1]) and also for management and forecasting purposes (Friedman et al. [2]; Arhonditsis and Brett [3]). Today, a large variety of these models is available and they are increasingly being acknowledged for their role in assisting ecosystem management practices (Trolle et al. [4]).

The decline over the past 30 to 40 years of water quality in the Te Arawa (Rotorua) lakes and in New Zealand lakes generally has been linked to nutrient loads associated with land development for agriculture, including increasing stock density and use of artificial fertilisers (Hamilton [5]). Steps are beginning to be taken to redress the decline in water quality, including changing land use around some lakes. The focus site for the present study is Lake Rotorua, located adjacent to Rotorua city and a major tourism, fishing and cultural asset to the Rotorua region. Water quality in Lake Rotorua has declined progressively over the past four decades (e.g. Rutherford et al. [6]; Burger et al. [7]) to the extent that some recreational activities have been jeopardised. As a result an Action Plan has been proposed by Bay of Plenty Regional Council (BoPRC) to improve water quality. Because of the complexity of both spatial and temporal variations in catchment nutrient loads, and the way in which Lake Rotorua responds to these loads, an interdisciplinary modelling approach was considered the best way in which to allow quantitative assessments of the water quality effects of different land uses, climates and in-lake actions for the purposes of managing lake water quality.

The model application in this study was based on the coupled onedimensional lake ecosystem model DYRESM-CAEDYM (developed at the Centre for Water Research, University of Western Australia). The ecological model CAEDYM has a relatively simple process representation of sediment nutrient dynamics even though it has proven remarkably successful in 
reproducing seasonal changes in concentrations of nutrients in lake bottom waters induced from sediment releases (e.g. Burger et al. [7]; Trolle et al. [8]; Özkundakci et al. [9]). The model regulates the sediment phosphate and ammonium releases according to concentrations of dissolved oxygen (DO) and nitrate, and water temperature in the overlying water layer. Changes in sediment nutrient releases in the model thus reflect only the relevant water layer variables and not any changes in sediment nitrogen $(\mathrm{N})$ or phosphorus $(\mathrm{P})$ content or any other processes that might affect nutrient releases. Changes in external nutrient loading, however, will likely feed back to changes in sediment oxygen demand (SOD) and nutrient releases, leading to a new equilibrium between external and internal loading (Søndergaard et al. [10]). In the case of Lake Rotorua (Rutherford et al. [6]) calculated a time for near-complete equilibrium of sediments of up to 195 years, but noted quite rapid and substantial reductions in sediment nutrient releases, because of reduced levels of both nutrient loading and deoxygenation in the water column, with associated improvements in water quality. The lack of feedback between the water column and the bottom sediment composition in the current version of CAEDYM has been described previously, but has not been adequately accounted for in past lake model simulation efforts (Trolle et al. [8]; Özkundakci et al. [9]).

In the current model application using CAEDYM, and based on the considerations of Rutherford et al. [6], we sought to account for the effect of external nutrient loads on SOD and nutrient release by adjusting relevant sediment parameters in CAEDYM based on changes in total external $\mathrm{N}$ loading to the lake. Our approach built upon results from Trolle et al. [11] who noted moderate reductions in nutrient concentrations of bottom sediments in Lake Rotorua between 1995 and 2006, though they did not link this quantitatively to nutrient loads.

\section{Methods}

\subsection{Study site}

Lake Rotorua (Figure 1) is a shallow (mean depth $10.8 \mathrm{~m}$ ), large lake (area 80.8 $\mathrm{km}^{2}$ ), in the Bay of Plenty of the Central Volcanic Plateau of North Island, New Zealand. The lake is the largest of the Te Arawa lakes in the region and is classified eutrophic, with annual mean concentrations of total phosphorus (TP) and total nitrogen (TN) of 0.055 and $0.814 \mathrm{mg} \mathrm{L}^{-1}$, respectively (Burger [12]). It is a polymictic lake and stratifies several times during summer when there are substantial sediment nutrient releases associated with bottom water oxygen depletion (Burger [12]). The lake catchment $\left(425 \mathrm{~km}^{2}\right)$ comprises mainly agriculture $(48 \%)$ and plantation forestry $(23 \%)$. 


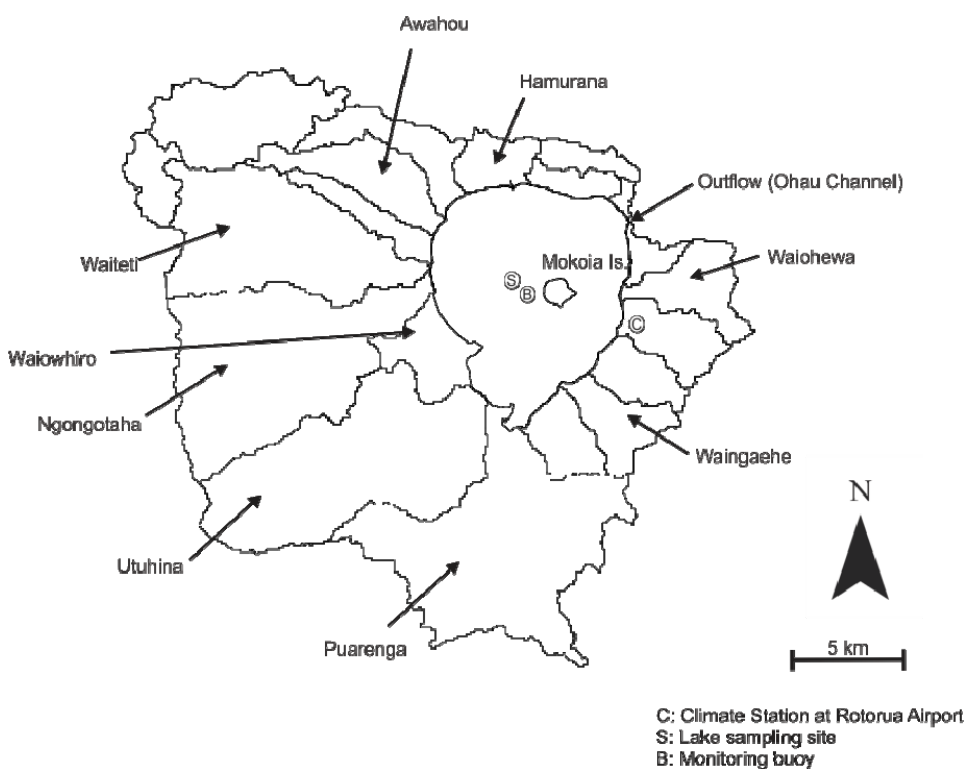

Figure 1: Map of the Lake Rotorua catchment with details of major subcatchments, and showing the BoPRC sampling site, high-frequency monitoring buoy and Rotorua airport weather station. Mokoia Island is the closed circle in the centre of the lake.

\subsection{Model description}

In this study, water quality in Lake Rotorua was simulated using the onedimensional (1D) hydrodynamic model DYRESM (version 3.1.0-03), which was coupled with the aquatic ecological model CAEDYM (version 3.1.0-06), both developed at the Centre for Water Research, The University of Western Australia. DYRESM resolves the vertical distribution of temperature, salinity, and density, and the vertical mixing processes in lakes and reservoirs. CAEDYM simulates time-varying fluxes that regulate concentrations of biogeochemical variables (e.g., nutrient species, phytoplankton biomass). The model includes comprehensive process representations for carbon (C), N, P, and DO cycles, and several size classes of inorganic suspended solids. Several applications have been made of DYRESM-CAEDYM to different lakes (e.g. Burger et al. [7]; Trolle et al. [8]; Gal et al. [13]; Özkundakci et al. [9]) and these publications have detailed descriptions of the model equations.

The biogeochemical variables in CAEDYM may be configured according to the goals of the model application and availability of data. In this study, three groups of phytoplankton were included in CAEDYM, representing generically cyanophytes (without $\mathrm{N}$-fixation), diatoms, and a combined group termed chlorophytes. Some of the major fluxes influencing $\mathrm{N}$ and $\mathrm{P}$ cycling in the model are represented in Figure 2, including phytoplankton growth and loss, sediment mineralisation and decomposition of particulate organic matter. 


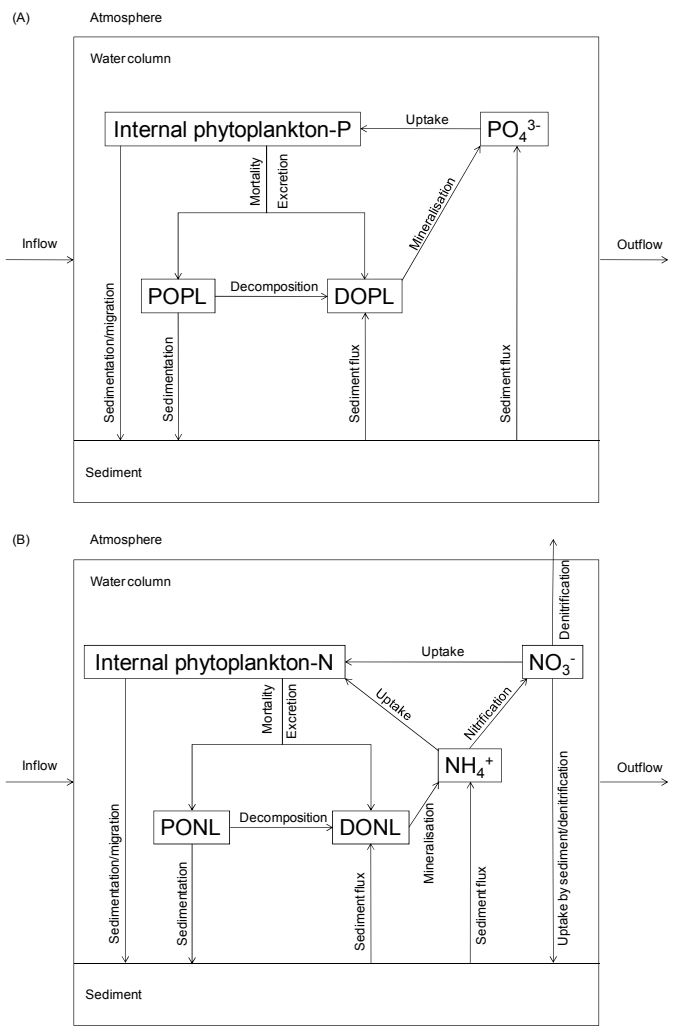

Figure 2: Conceptual model of (A) phosphorus and (B) nitrogen cycles represented in DYRESM-CAEDYM for the present study. POPL, PONL, DOPL and DONL represent particulate labile organic phosphorus and nitrogen, and dissolved labile organic phosphorus and nitrogen, respectively.

CAEDYM has been shown to be capable of reproducing seasonal variability in sediment fluxes of nutrients, but the flux of dissolved nutrients from bottom sediments to the water is not directly linked to the particulate organic matter flux into the sediments. Fluxes of dissolved inorganic and organic nutrients from the bottom sediments $(D S F)$ are dependent on temperature, nitrate and DO concentrations of the water layer immediately above the sediment surface:

$$
f_{g}^{D S F}=\vartheta_{g}^{T-20} S_{g}\left(\frac{K_{O x_{g}}}{\left.K_{\text {Oxg }}+\sum \text { (oxidants }\right)}\right) \frac{1}{\Delta z_{\text {bot }}}
$$

where the subscript $g$ used here is a generic identifier for phosphate or ammonium, $v$ is a temperature multiplier, $S_{g}$ is the maximum flux at $20^{\circ} \mathrm{C}, K_{O x}$ is a half-saturation constant that relates the flux to the overlying concentration of 
oxidants (i.e., DO and nitrate for phosphate release, and DO for ammonium release), and $\Delta_{z b o t}$ is the thickness of the layer above the sediment. The model for $S O D$ is given by:

$$
f_{S O D}=\vartheta_{S O D}^{T-20} S_{g}\left(\frac{D O}{D O+K_{S O D}}\right) \frac{1}{\Delta z_{b o t}}
$$

where $K_{S O D}$ is the half-saturation constant that determines how $S O D$ is influenced by water column DO. The calibration of parameters is specific to each new application, but there is an extensive parameter library available from the large number of studies undertaken with the model. The model was run at hourly time steps between July 2001 and June 2009, with daily averaged input data and daily output data at $0900 \mathrm{~h}$. A comprehensive description of input data used for the present model application, including meteorological forcing data and catchment-derived nutrient loadings can be found in Hamilton et al. [14] and Rutherford et al. [15].

DYRESM-CAEDYM was calibrated against samples collected monthly by BoPRC from the centre of the lake (Figure 1). Calibration was for a four-year period between July 2005 and June 2009 for variables of temperature, DO, phosphate, TP, ammonium, nitrate and TN at the water surface $(0 \mathrm{~m})$, at a depth of $15 \mathrm{~m}$, and near the bottom (depth of $19 \mathrm{~m}$ ). Modelled chlorophyll $a$ concentration was calibrated against measured surface chlorophyll $a$. Model parameters were adjusted using a trial and error approach with values set to within literature ranges (e.g. Trolle et al. [8]). A comprehensive review of the model performance is given in Hamilton et al. [14].

\subsection{Sediment parameterisation}

During the calibration/validation period, sediment parameters (i.e. SOD and sediment nutrient release rates) were adjusted to obtain a good fit with water column measurements using parameter values within the range observed by Burger et al. [16] in a benthic chamber experiment. For simulation periods outside the calibration/validation period (for water quality hindcasting and forecasting purposes), we used empirical relationships between $\mathrm{N}$ loads (Figure 3) and measured values of volumetric hypolimnetic oxygen demand (VHOD) (Vant [17]) and sediment N concentrations Trolle et al. [18]. Sediment $\mathrm{N}$ concentrations for earlier time periods were derived from measured particulate $\mathrm{N}$ concentrations of horizontal layers of dried cores. The age of the layer was estimated by the time since the Tarawera eruption (1886), based on the layer height above the tephra divided by the total sediment depth above the tephra, and then multiplied by the total number of years (120) between sample collection and the eruption. The Tarawera tephra has previously been described by Pullar and Kennedy [19] as a dark-coloured coarse material, which is very distinctive and can readily be distinguished visually within a sediment sample. Using tephras from volcanic eruptions has also been used by Trolle et al. [11] and Pearson et al. [20] to determine sedimentation rates following tephra deposition. 


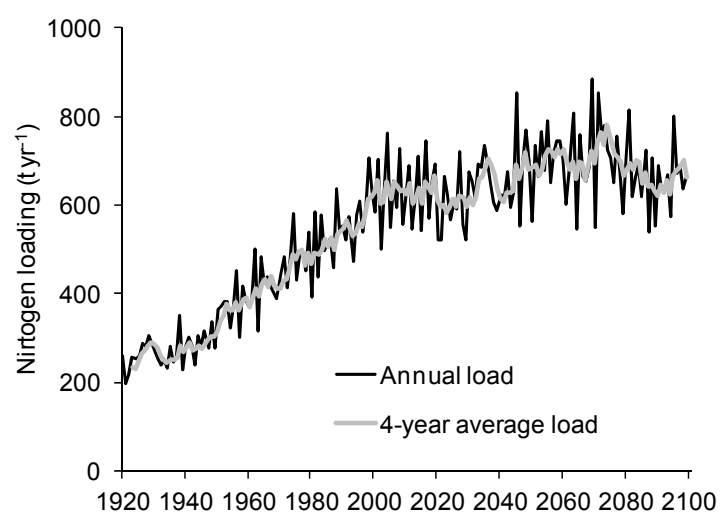

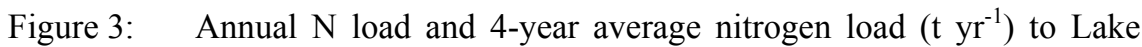
Rotorua based on ROTAN R0 (present land use scenario) output. Nitrogen loads were obtained from Rutherford et al. [15].

\section{Results}

Figure 4(A) shows a linear and an exponential relationship between measured VHOD values (Vant [17]) and the preceding 4-year average annual $\mathrm{N}$ load to Lake Rotorua. The exponential function was used to describe the relationship between these two variables based on the assumption that the VHOD would never be zero for any given $\mathrm{N}$ load $>0$. However, this model would likely overestimate VHOD with increasing $\mathrm{N}$ loads. Therefore, the linear model was adopted to predict VHODs for $\mathrm{N}$ loads $>390 \mathrm{t} \mathrm{yr}^{-1}$ (i.e., an $\mathrm{N}$ load corresponding to intercept of the linear model on the $\mathrm{x}$-axis) and the exponential model to

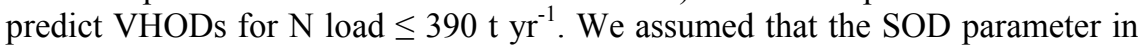
CAEDYM was proportional to VHOD modelled using the empirical relationship described above.
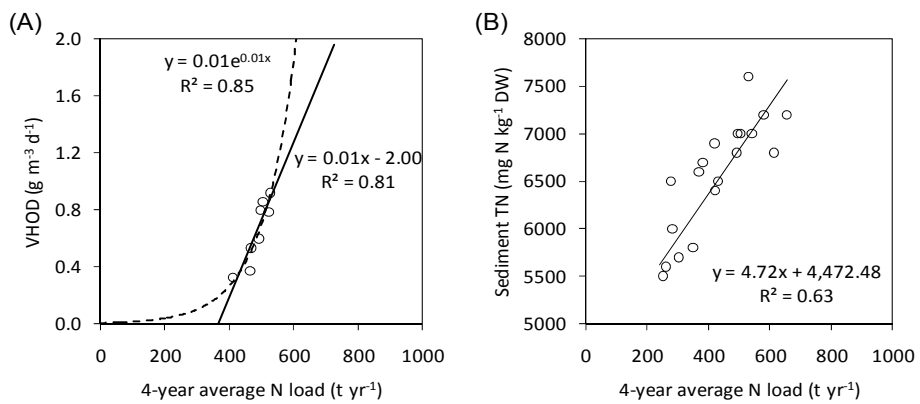

Figure 4: (A) Linear and exponential relationships between VHOD and 4year average of annual $\mathrm{N}$ load to Lake Rotorua, (B) Linear relationship between sediment $\mathrm{TN}$ concentrations and 4-year average $\mathrm{N}$ loads. 
(A)

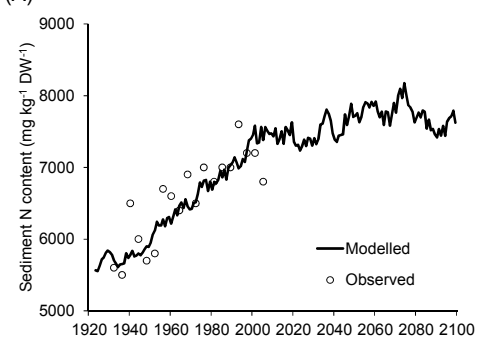

(C)

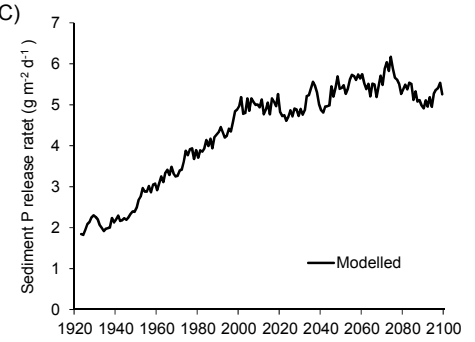

$(\mathrm{E})$

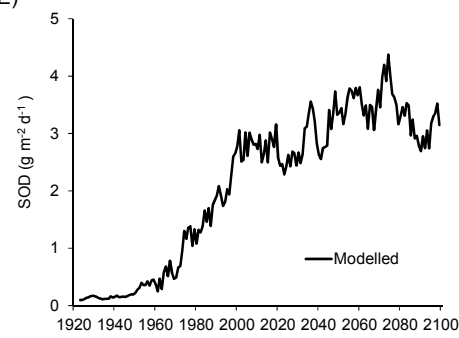

(B)

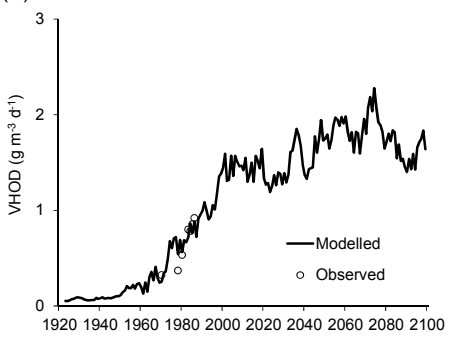

(D)

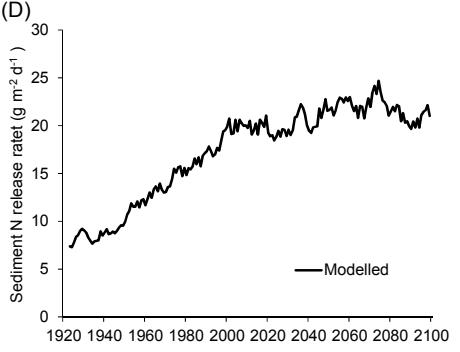

Figure 5: Time series of simulated and observed values of (A) sediment $\mathrm{N}$ concentrations, (B) volumetric hypolimnetic oxygen demand (VHOD), simulated (C) sediment phosphate release rates, (D) sediment ammonium release rates, and (E) sediment oxygen demand (SOD) for 1920-2100. Detailed descriptions of derivation methods are given in the text.

Figure 4(B) shows a linear relationship of the preceding 4-year average $\mathrm{N}$ load and the measured sediment $\mathrm{N}$ concentration, indicating that four years is a suitable duration over which sediments may respond to changes in external loading. By using the Tarawera eruption in 1886 as a sediment marker, it was possible to compare the sediment total $\mathrm{N}$ concentration corresponding to different time periods against the 4-year average $\mathrm{N}$ load for that time period, and derive a relationship, which could then be used to estimate sediment TN concentrations from 4-year average $\mathrm{N}$ load for each year simulated in DYRESMCAEDYM. We assumed that the maximum potential ammonium release rate would be directly proportional to the sediment $\mathrm{N}$ concentration predicted from the 4-year average $\mathrm{N}$ load. Phosphate release rates were calculated by assuming 
that the ratio of nitrogen and phosphorus in lake sediments would remain constant over the entire period 1921-2099, i.e. a constant ratio of ammonium:phosphate release.

Figure 5 shows the modelled and observed sediment $\mathrm{N}$ concentrations and VHOD for the simulation period 1920-2100. This figure also shows the modelled sediment $\mathrm{P}$ and $\mathrm{N}$ release rates and SOD for this period. The modelled sediment $\mathrm{N}$ release rates follow the pattern of the 4-year average $\mathrm{N}$ load according to the linear relationship established in Figure 4(B) (and similarly for $\mathrm{P}$ based on the sediment ratio of $\mathrm{N}: \mathrm{P}$ ). Modelled VHOD and SOD follow the $\mathrm{N}$ load according to either the linear or exponential relationships described by Figure 4(A) (> 390 and $\leq 390 \mathrm{t} \mathrm{N} \mathrm{yr}^{-1}$, respectively).

\section{Discussion}

The objective of this study was to overcome the static nature of the simplistic process representation of the sediment-water interface solute exchanges in CAEDYM by using empirical modelling to define relevant parameters. This refinement enabled the sediment fluxes to be prescribed in a quasi-dynamic way using a model application to Lake Rotorua spanning two centuries. By relating external loading of nitrogen to the vertically-varying concentrations of sediment TN and VHOD, the parameters in CAEDYM, which regulate sediment inorganic nutrient fluxes and SOD, were more effectively able to reflect the major changes in organic matter loading to the sediments that were likely to be associated with these variations in nutrient loading. A 4-year average $\mathrm{N}$ load explained $63 \%$ of the variation in sediment $\mathrm{TN}$ concentrations observed in the vertical profile, implying that a reduction in external loading will eventually lead to a reduction in internal nutrient loading.

A further implication of this relationship is that the distribution of nutrients in the bottom sediments of Lake Rotorua may be strongly influenced by different land uses, which are associated with variations in nutrient loading (Hamilton [5]) and thus trophic state of the lake. Trolle et al. [18], however, found that lake trophic state was not related to sediment $\mathrm{N}$ content in 14 lakes in the region and showed that in-situ diagenetic processes, including density-differentiated burial and biodiffusive mixing, were more important predictors of the vertical concentration gradients of sediment $\mathrm{N}$ content than lake trophic state. It is worth noting that the trophic state indicator in Trolle et al. [18] was based on annual average water column attributes between 2005 and 2006 and may have therefore represented an abridged period, relative to the four-year one used in this study, to be significantly related to sediment nutrient dynamics. Jeppesen et al. [21], for example, showed that the recovery of 35 Danish lakes, where external phosphorus loads were reduced, was delayed due to internal loading. They found periods up to 15 years before a new equilibrium between sediment $\mathrm{P}$ and water column P content was reached. The importance of long-term sediment responses to external loading is further supported by the observation that sediment $\mathrm{TN}$ content in Lake Rotorua was more strongly correlated with external loading using a 4-year average than with annual loading. 
The relatively strong positive relationship between external $\mathrm{N}$ load and VHOD in this study is consistent with other studies. Matthews and Effler [22], for example, found that a rapid decrease of hypolimnetic oxygen demand in Onondaga Lake, New York, was driven by a decrease in organic matter loading to the bottom waters.

Long-term estimates of external $\mathrm{P}$ loadings to Lake Rotorua beyond the calibration/validation period of the model were not available for this study. The relationship between external $\mathrm{P}$ loading and sediment $\mathrm{P}$ content may have been difficult to establish. For instance, Søndergaard et al. [10] demonstrated that sediment $\mathrm{P}$ content was better predicted using a combination of external $\mathrm{P}$ loading and sediment iron content, compared with using external P loading alone. The relationship between external $\mathrm{P}$ loading and sediment $\mathrm{P}$ content is further complicated by post-depositional mobility of phosphorus within the sediment profile (Carignan and Flett [23]). Therefore, instead of using external $\mathrm{P}$ loading to predict sediment $\mathrm{P}$ release rates, we assumed a constant ratio of N:P release rates. The ratio of the calibrated release rates of $\mathrm{N}: \mathrm{P}$ for the calibration/validation period was 6.3 and was remarkably close to the average $\mathrm{N}: \mathrm{P}$ ratio of the measured sediment profile of $\mathrm{N}$ and $\mathrm{P}$ (6.5). Trolle et al. [11] sampled surficial sediments in 12 lakes in the Rotorua region for which the N:P ratio averaged 6.3 for four eutrophic lakes.

The $\mathrm{N}$ concentration of surface sediment and VHOD in Lake Rotorua depended on external $\mathrm{N}$ load, and this relationship was used to infer sediment parameters in CAEDYM to dynamically account for long-term changes in external nutrient loading. While the relationship developed in this study must be considered site specific and should not be extrapolated to other lakes, future modelling studies in other systems should consider the development of similar simple empirical relationships between external loads and sediment nutrient content where the objective is to simulate long-term (decadal) water column responses to significant changes in external loading. A more complex diagenetic model is available within CAEDYM, but it is very computationally demanding Oldham et al. [24], making it unsuitable for long-term simulations. Trolle et al. [4] also noted that data to validate complex diagenetic models rarely or never exist, presenting a major challenge in model validation over several decades. The method presented here provides a relatively simple empirical approach to dynamically account for the sediment feedback in response to major changes in external loading, and may be suitable for simulating extended periods necessary to better understand lake water quality responses to land use or climate change.

\section{References}

[1] Norberg, J. and DeAngelis, D., Temperature effects on stocks and stability of a phytoplankton-zooplankton model and the dependence on light and nutrients. Ecological Modelling 95, pp. 75-86, 1997.

[2] Friedman, R., C. S. Ansell, S. Diamond and Haimes, Y. Y., The use of models for water resources management, planning and policy. Water Resource Research 20, pp. 793-802, 1984. 
[3] Arhonditsis, G.B. and Brett, M.T., Eutrophication model for Lake Washington (USA) Part II - model calibration and system dynamics analysis. Ecological Modelling 187, pp. 179-200, 2005.

[4] Trolle, D., Hamilton, D.P., Hipsey, M.R., Bolding, K., Bruggeman, J., Mooij, W.M., Janse, J.H., Nielsen, A.., Jeppesen, E., Elliott, J.A., MaklerPick, V., Petzoldt, T., Rinke, K., Flindt, M.R., Arhonditsis, G.B., Gal, G., Bjerring, R., Tominaga, K., Hoen, J., Downing, A.S., Marques, D.M., Fragoso Jr., C.R., Søndergaard, M. and Hanson, P, A community-based framework for aquatic ecosystem models. Hydrobiologia 683, pp. 25-34, 2011.

[5] Hamilton, D.P., Land use impacts on nutrient export in the Central Volcanic Plateau, North Island. New Zealand Journal of Forestry 49: 2731, 2005.

[6] Rutherford, J.C., Dumnov, S.M. and Ross, A.H., Prediction of phosphorus in Lake Rotorua following load reductions. New Zealand Journal of Marine and Freshwater Research 30, pp. 383-396, 1996.

[7] Burger, D.F., Hamilton, D.P. and Pilditch, C.A., Modelling the relative importance of internal and external nutrient loads on water column nutrient concentrations and phytoplankton biomass in a shallow polymictic lake. Ecological Modelling 211, pp. 411-423, 2008.

[8] Trolle, D., Skovgaard, H. and Jeppesen, E., The Water Framework Directive: Setting the phosphorus loading target for a deep lake in Denmark using the 1D lake ecosystem model DYRESM-CAEDYM. Ecological Modelling 219, pp. 138-152, 2008.

[9] Özkundakci, D., Hamilton, D.P. and Trolle, D., Modelling the response of a highly eutrophic lake to reductions in external and internal nutrient loading. New Zealand Journal of Marine and Freshwater Research 45, pp. 165-185, 2011.

[10] Søndergaard, M., Windolf, J. and Jeppesen, E, Phosphorus fractions and profiles in the sediment of shallow Danish lakes as related to phosphorus loads, sediment composition and lake chemistry. Water Research 30, pp. 992-1002, 1996.

[11] Trolle, D., Hamilton, D.P., Hendy, C. and Pilditch, C., Sediment and nutrient accumulation rates in sediments of twelve New Zealand lakes: influence of lake morphology, catchment characteristics and trophic state. Marine and Freshwater Research 59, pp. 1067-1078, 2008.

[12] Burger, D.F., 2006. Benthic-pelagic coupling of nutrients in Lake Rotorua. Ph.D. Thesis, Department of Biological Sciences, University of Waikato, Hamilton, 139p.

[13] Gal, G., Hipsey, M.R., Parparov, A., Wagner, U., Makler, V. and Zohary, T., Implementation of ecological modelling as an effective management and investigation tool: Lake Kinneret as a case study. Ecological Modelling 220, pp. 1697-1718, 2009.

[14] Hamilton, D., Özkundakci, D., McBride, C, Ye, W., Silvester, W. and White, P., Prediction of the effects of nutrient loads, management regimes 
and climate change on water quality of Lake Rotorua. CBER Report 123, University of Waikato, Hamilton, New Zealand, 71p, 2011.

[15] Rutherford, K., Palliser, C. and Wadhwa, S., Prediction of nitrogen loads to Lake Rotorua using the ROTAN model. NIWA client report: HAM2010134, 183p, 2011.

[16] Burger, D.F., Hamilton, D.P., Gibbs, M.M. and Pilditch, C.A., Benthic nutrient fluxes in a polymictic, eutrophic lake. Hydrobiologia 584: 13-25, 2007.

[17] Vant, W.N. (Ed.), Lake Managers Handbook. Water and Soil Miscellaneous Publication No. 183, ISSN 0110-4705, 230p, 1987.

[18] Trolle, D., Hamilton, D.P. and Pilditch, C.A., Evaluating the influence of lake morphology, trophic status and diagenesis on geochemical profiles in lake sediments. Applied Geochemistry 25, pp. 621-632, 2010.

[19] Pullar, W.A. and Kennedy, N.M., Tephra deposits in the Rotorua Lakes District. In: Chapman, V.J. (Ed.), Handbook of the Rotorua Lakes District. The Guardians of the Rotorua Lakes, pp. 23-25, 1981.

[20] Pearson, L.K., Hendy, C.H., Hamilton, D.P. and Picket, R.C., Natural and anthropogenic lead in sediments of the Rotorua lakes, New Zealand. Earth and Planetary Science Letters 297, pp. 536-544, 2010.

[21] Jeppesen, E., Søndergaard, M., Jensen, J.P., Havens, K.E., Anneville, O., Carvalho, L., Coveney, M.F., Deneke, R., Dokulil, M.T., Foy, B., Gerdeux, D., Hampton, S.E., Hilt, S., Kangur, K.L., Köhler, J.K., Lammens, E.H.H.R., Lauridsen, T.L., Manca, M., Miracle, M.A.R., Moss, B., Ges, P.N., Persson, G., Phillips, G., Portielje, B., Romo, S., Schelske, C.L., Straile, D., Tatrai, I., Wille, E. and Winder, M., Lake responses to reduced nutrient loading - an analysis of contemporary long-term data from 35 case studies. Freshwater Biology 50, pp. 1747-1771, 2005.

[22] Matthews, D.A. and Effler, S.W., Long-Term Changes in the Areal Hypolimnetic Oxygen Deficit (AHOD) of Onondaga Lake: Evidence of Sediment Feedback. Limnology and Oceanography 51, pp. 702-714, 2006.

[23] Carignan, R. and Flett, R.J., Postdepositional mobility of phosphorus in lake sediments. Limnology and Oceanography 26, pp. 361-366, 1981.

[24] Oldham, C.E., Salmon, S.U.J., Hipsey, M.R. and Ivey, G.N., Modelling pit lake water quality: Coupling of lake stratification dynamics, lake ecology, aqueous geochemistry and sediment diagenesis. In Mine Pit Lakes: Characteristics, Predictive Modeling, and Sustainability, Society for Mining, Metallurgy, and Exploration, Inc., USA, pp. 127-136, 2009. 